\title{
BMJ Open Timing of household food insecurity exposures and asthma in a cohort of US school-aged children
}

\author{
Lauren D Mangini, ${ }^{1}$ Mark D Hayward, ${ }^{2}$ Yeyi Zhu, ${ }^{3}$ Yongquan Dong, ${ }^{4}$ \\ Michele R Forman ${ }^{5}$
}

To cite: Mangini LD, Hayward MD, Zhu Y, et al. Timing of household food insecurity exposures and asthma in a cohort of US school-aged children. BMJ Open 2018;8:e021683. doi:10.1136/ bmjopen-2018-021683

- Prepublication history for this paper is available online. To view these files, please visit the journal online (http://dx.doi org/10.1136/bmjopen-2018021683).

Received 12 January 2018 Revised 11 July 2018 Accepted 24 September 2018

Check for updates

(c) Author(s) (or their employer(s)) 2018. Re-use permitted under CC BY-NC. No commercial re-use. See rights and permissions. Published by BMJ.

${ }^{1}$ Department of Nutritional Sciences, The University of Texas at Austin, Austin, Texas, USA

${ }^{2}$ Department of Sociology and Population Research Center, The University of Texas at Austin, Austin, Texas, USA

${ }^{3}$ Division of Research, Kaiser Permanente Northern California, Oakland, California, USA

${ }^{4}$ Office of Medicine- Health Services Research, Baylor College of Medicine, Houston, Texas, USA

${ }^{5}$ Department of Nutrition Science, Purdue University, West Lafayette, Indiana, USA

Correspondence to

Dr Lauren D Mangini; mangini@mail.utexas.edu

\section{ABSTRACT}

Objective Food insecurity is positively associated with asthma, the most common chronic childhood disease, yet directionality is unclear. The objective was to determine the association between exposure to food insecurity in early childhood and the odds of asthma later in childhood. Design Data from four waves of the Early Childhood Longitudinal Study-Kindergarten (ECLS-K) cohort, a prospective, dual-frame, multistage probability cluster sampling study of school-aged US children were entered in multivariate logistic regression models, adjusted for covariates. Exposures to food insecurity were based on parental responses to the validated USDA 18-item module at each wave.

Setting Public and private primary and secondary schools between 1998 and 2007.

Participants At its inception (1999), the ECLS-K had 20578 kindergarteners; by the spring of eighth grade (2007), the cohort dropped to 9725 due to attrition. Children missing an exposure, outcome or confounding variable were excluded, final $n=6731$.

Primary outcome measure Child's diagnosis of asthma by a healthcare professional as reported by the parent.

Results Household food insecurity (vs food security) in the year before kindergarten and in second grade had a higher odds of asthma by $18 \%(95 \% \mathrm{Cl} 1.17$ to 1.20$)$ and $55 \%$ (95\% Cl 1.51 to 1.55). After removing asthmatics before third grade from the model, food insecurity in second grade was associated with higher odds of asthma at fifth or eighth grades (OR 1.55; 95\% $\mathrm{Cl} 1.53$ to 1.58), whereas food insecurity in the year before kindergarten had a lower odds at fifth or eighth grades.

Conclusions Food insecurity in the year before kindergarten and in second grade were associated with a higher odds of asthma in third grade. Food insecurity in second grade retained the signal for increased odds of asthma after third and through eighth grades. Additional research is needed to explore childhood windows of vulnerability to asthma.

\section{INTRODUCTION}

Food insecurity, defined as limited or uncertain availability of nutritionally adequate food or an inability to reliably acquire it, is a serious concern for US children. ${ }^{1}$ When poverty and other related factors are controlled, children in food-insecure households are more

\section{Strengths and limitations of this study}

- Strengths include multiple waves of the Early Childhood Longitudinal Study-Kindergarten (ECLS-K) cohort, a diverse national sample of school-aged children and repeated measures of food insecurity exposure based on the 18-item validated Household Food Security Survey Module.

- Use of a validated short-form of the Center for Epidemiologic Studies Depression (CES-D) Scale is a strength.

- Limitations include no data collection for family history of asthma or environmental exposures associated with asthma, such as maternal smoking or child exposure to air pollutants.

- Loss to follow-up in the ECLS-K cohort was a limitation.

likely than the food-secure to suffer health problems such as higher rates of iron deficiency and adverse behavioural, emotional and academic outcomes. ${ }^{2-4}$ In 2016, the percentage of food insecurity in households with children $<18$ years old was higher than the national average for households without children $\left(16.5 \%\right.$ vs $10.5 \%$, respectively). ${ }^{5}$ Indeed, the higher percentages of food insecurity in households with children underscore the importance of the American Academy of Pediatrics guidelines to screen children for food insecurity and the potential for access to nutrition assistance and other supportive programmes. $^{6}$

Food insecurity is a complex phenomenon, with underlying biosocial pathways. Maternal depression, race/ethnicity and obesity are potential factors amidst these pathways. In cross-sectional and longitudinal studies, maternal depression is associated with and an independent predictor of food insecurity, respectively. ${ }^{7-9}$ Belonging to a minority race/ethnicity, specifically non-Hispanic Black (NHB) and/or Hispanic, is associated with food insecurity. ${ }^{5}$ Food insecurity and obesity are positively associated in adult 
women; some studies have shown a similar association in children. ${ }^{10-15}$ Childhood obesity is also positively associated with asthma, the most common chronic childhood disease. ${ }^{16-18}$ These potential factors may interact in clusters or chains of risk to impact later chronic disease risk and development. ${ }^{19}$ Recognising the obesity-asthma connection and the more elusive, but complex, relationship between food insecurity and obesity, the question arises whether exposure to food insecurity in early childhood is associated with asthma in US children. This question gains credence from a Canadian study of children and youth, in which experiencing two or more episodes of hunger from ages 6 to 11 more than doubled the odds of asthma in adolescents aged 16-21; food insecurity was not measured in the study. ${ }^{20}$

We reported that food insecurity is associated with a higher odds of asthma in third graders in the Early Childhood Longitudinal Study-Kindergarten (ECLS-K) cohort, in accord with another cross-sectional study. ${ }^{21} 22$ The association between food insecurity and asthma, however, lacks directionality to determine which came first. The question of timing of exposure and onset and development of chronic disease holds importance for both chronic disease prevention and its management. Importantly, life course research suggests that during childhood development, sensitive periods exist during which an exposure such as food insecurity could have an effect on chronic disease risk or development magnified beyond any effect of an exposure outside of the period. ${ }^{23}$ The objective of this paper, therefore, was to go beyond the reported cross-sectional association and determine the association between exposure to food insecurity in early childhood and the odds of asthma later in childhood in the prospective ECLS-K study, controlling for obesity and other covariates.

\section{METHODS}

\section{Subjects}

The ECLS-K was a prospective cohort study of kindergarteners in US schools in the fall of 1998 who were followed through the spring of eighth grade in 2007. The study had a dual-frame, multistage probability cluster sampling design and was initially representative of all US kindergarteners at its inception/kindergarten year. In this paper, we focused on the four time points with parent-reported data of interest, that is, the spring of kindergarten (1999) and third (2002), fifth (2004) and eighth (2007) grades, using the public-use data set. ${ }^{24}$ Thus, the analysis was designed to explore food insecurity in the kindergarten and third grade waves as independent variables, and asthma as reported in the third grade and then in the fifth and eighth grade waves as dependent variables.

In the spring of 1999, the cohort had 20578 kindergarteners that dropped to 9725 by the spring of eighth grade (2007) due to attrition. ${ }^{24}$ If twins were sampled, only one twin was randomly selected and eligible to exclude duplicate household data. Children $(n=2994)$ with the following missing data were excluded: household food security, parent report of asthma diagnosis, sex, race/ ethnicity, maternal nativity, poverty, health insurance coverage and/or parental depression at any wave, or body mass index (BMI) in the spring of kindergarten (1999). The final unweighted sample for the analysis was 6731. To assess potential bias, we compared the characteristics of children with missing covariate data with the analytic sample and report a slightly smaller proportion of non-Hispanic Whites (NHWs) than in the sample (66.9\% vs $67.7 \%$, respectively). All procedures involving data from human subjects were approved by the institutional review board at the University of Texas at Austin.

\section{Patient and public involvement}

Patients and the public were not involved in this study.

\section{Measures}

Food insecurity

Food insecurity was measured using the validated USDA 18-item Household Food Security Survey Module (HFSSM) as described previously. ${ }^{51}$ The HFSSM was administered by telephone to the parent to assess food security status in the child's household over the prior 12 months. By a positive parental response to three or more items, the child's household was classified as food insecure at some time during the previous year. Therefore, for both the year prior to kindergarten and in second grade (ie, the year prior to the spring of third grade), households were classified as food insecure if $\geq 3$ of the 18 questions were affirmed, otherwise food secure. ${ }^{25}$

\section{Asthma diagnosis}

Asthma was assessed by a yes/no response to a single national survey/surveillance question, asking whether the parent had ever been told by a healthcare professional that the child had asthma, in the spring of third (2002), fifth (2004) and eighth (2007) grades. ${ }^{26}$ If the item was affirmed at the third grade wave, the child was classified as diagnosed with asthma at any time between birth and the spring of third grade. If affirmed at fifth or eighth grade only, the child was classified as diagnosed after the spring of third grade.

\section{Covariates}

Sociodemographic and anthropometric characteristics related to household food insecurity and asthma included household poverty, child race/ethnicity, sex, health insurance coverage and BMI and maternal nativity and parental depression. Household poverty was calculated from a comparison of the income range of the household reported in the spring of kindergarten to 1998 Census poverty thresholds, which took into account household size. Households were dichotomised as at/above or below the poverty threshold in the year prior to kindergarten. ${ }^{24}$ Child race/ethnicity and sex were parent-reported in kindergarten. ${ }^{24}$ Race/ethnicity was classified as NHW, NHB, Hispanic (of any race) or Asian/Other, sex as male or female. 
If any country of origin other than the USA was reported, maternal nativity was classified as 'foreign-born'; otherwise, a mother was classified as 'U.S.-born.' Parental depression in the spring of kindergarten and third grade was determined by responses to the validated 12-item Center for Epidemiologic Studies Depression Scale (CES-D) and scored as described previously. ${ }^{27}$ Parents were classified as either not depressed or depressed at those two waves, with over $90 \%$ of respondents being the mothers. Child health insurance was based on a one-item response from the spring of kindergarten parent questionnaire that asked whether the child currently had health insurance. A child was classified as being insured if the response was affirmative, otherwise uninsured.

The average of two measurements for height using the ShorrBoard (Olney, MD) and for weight using a digital scale at the spring of kindergarten was used in the analyses. ${ }^{24}$ We previously described exclusion criteria and data cleaning for anthropometrics. ${ }^{21}$ At the spring of kindergarten, a BMI percentile was calculated from a child's mean height and weight using the Centers for Disease Control and Prevention age-specific and sex-specific referent data, and classified as lean/normal $(<85$ th percentile), overweight (85th-94th percentile) or obese ( $\geq 95$ th percentile). ${ }^{28}$ Given the recognised association of overweight/obesity and childhood asthma, we used kindergarten BMI, the earliest measurement available in this sample, in our models. ${ }^{17}$

\section{Analyses}

We generated frequencies for food security, asthma, sociodemographic and anthropometric variables in the final sample for each wave using unweighted data. Using sample weights from the public data set, we compared the variables by calculating $\chi^{2}$ tests and also performed all other analyses. Two multiple logistic regression models generated crude and adjusted OR with 95\% CI for an asthma diagnosis by exposure to food insecurity. The first model estimated the OR of an asthma diagnosis at third grade by exposure first to food insecurity in the year prior to kindergarten, then by exposure in the years prior to kindergarten and third grade. The second model estimated the OR of an asthma diagnosis at fifth or eighth grade (vs never diagnosed, after excluding children diagnosed by third grade) by exposure to food insecurity in second grade, that is, the year prior to third grade. Logistic models were weighted using the longitudinal sample weights supplied with the data set. All analyses were conducted using SPSS V.23 (IBM, New York, USA) with $\mathrm{p}$ values $<0.05$ considered statistically significant.

\section{RESULTS}

The percentage of children with a parent-reported diagnosis of asthma was $10.9 \%(734 / 6731)$ at the third grade wave and $8.4 \%(502 / 5997)$ at the fifth or eighth grade wave after excluding those reporting asthma earlier (table 1). Compared with those children not diagnosed with asthma at third grade, those with a diagnosis after third grade had higher percentage of household food insecurity in the years prior to kindergarten and third grade, higher percentages of parental depression in kindergarten and third grade, higher percentages of poverty in the year prior to kindergarten, were more likely to be NHB, Hispanic or Asian/Other, were more likely to be male, had higher percentages of US maternal nativity and health insurance coverage in kindergarten and were more likely to be obese and less likely to be normal/ lean (table 1). The second set of comparisons, for children not diagnosed versus diagnosed at fifth or eighth grade, had similar results, with the exception that those diagnosed with asthma were more likely to be NHW and less likely to be Hispanic compared with their undiagnosed counterparts (table 1).

The percentage of children that were exposed to household food insecurity in the year prior to the spring of kindergarten was $6.9 \%$, in the year prior to spring of third grade, $5.7 \%$ (table 2). At both the kindergarten and third grade waves, the percentage of parental depression and household poverty was higher in the food-insecure (vs food-secure) children. Fewer NHW children versus other race/ethnicities were food insecure at either wave (table 2). Fewer children of US-born mothers (vs foreign-born) or uninsured (vs insured) children were food insecure at either wave (table 2). At both the kindergarten and third grade waves, there were higher percentages of food-insecure children (vs food-secure) living in poor households and fewer food-insecure children had normal/lean BMIs compared with their food-secure counterparts (table 2).

Household food insecurity in the year prior to kindergarten was associated with a $29 \%$ higher odds of asthma (95\% CI 1.26 to 1.29 ) in the crude model and a $33 \%$ higher odds of asthma in third grade (95\% CI 1.31 to 1.34) adjusting for all covariates except food insecurity in the year before third grade (table 3 ). The OR dropped to $18 \%$ (95\% CI 1.17 to 1.20 ) when food insecurity in the year before third grade was added. Food insecurity in the year before third grade was associated with a $53 \%$ higher odds of asthma (95\% CI 1.51 to 1.55) in the final model (table 3). Parental depression in the spring of kindergarten, being NHB, Hispanic or Asian/Other (vs NHW), being male (vs female) and being overweight or obese (vs normal/lean) were associated with higher odds of a third grade asthma diagnosis. Living in poverty (vs at or above poverty) in the year prior to kindergarten, having a foreign-born (vs US-born) mother and being uninsured (vs insured) in the year prior to kindergarten were associated with lower odds of a third grade asthma diagnosis (table 3). Including food insecurity in the year before third grade in the model resulted in a similar pattern of associations (table 3 ).

In table 4, all children diagnosed with asthma by third grade were removed. Compared with the food secure, food insecurity in the year prior to kindergarten was associated with lower odds of asthma at fifth and eighth grades (crude OR 0.96 (95\% CI 0.95 to 0.98 ); adjusted 
Table 1 Characteristics ( $n$, \%) of the ECLS-K cohort by asthma diagnosis at the third grade and fifth/eighth grade waves*

\begin{tabular}{|c|c|c|c|c|}
\hline & \multicolumn{2}{|c|}{$\begin{array}{l}\text { Third grade }(2002) \\
(n=6731)\end{array}$} & \multicolumn{2}{|c|}{$\begin{array}{l}\text { Fifth }(2004) \text { and eighth }(2007) \\
\text { grades }(n=5997)\end{array}$} \\
\hline & $\begin{array}{l}\text { No asthma } \\
(n=5997)\end{array}$ & $\begin{array}{l}\text { Asthma } \\
(\mathrm{n}=734)\end{array}$ & $\begin{array}{l}\text { No asthma } \\
(n=5495)\end{array}$ & $\begin{array}{l}\text { Asthma } \\
(n=502)\end{array}$ \\
\hline Household food insecurity in year before kindergarten & $405(6.8) \dagger$ & $62(8.4) \dagger$ & $359(6.5) \dagger$ & $46(9.2) \dagger$ \\
\hline Household food insecurity in year before third grade & $325(5.4) \dagger$ & $60(8.2) \dagger$ & $285(5.2) \dagger$ & $40(8.0) \dagger$ \\
\hline Parental depression in spring of kindergarten (yes) & $863(14.4) \dagger$ & $140(19.1) \dagger$ & $768(14.0) \dagger$ & $95(18.9) \dagger$ \\
\hline Parental depression in spring of third grade (yes) & $709(11.8) \dagger$ & $117(15.9) \dagger$ & $635(11.6) \dagger$ & $74(14.7) \dagger$ \\
\hline \multicolumn{5}{|l|}{ Household poverty in year before kindergarten } \\
\hline Below poverty level & $794(13.2) \dagger$ & $110(15.0) \dagger$ & $721(13.1) \dagger$ & $73(14.5) \dagger$ \\
\hline \multicolumn{5}{|l|}{ Race/ethnicity } \\
\hline NHW & $4111(68.6) \dagger$ & $456(62.1) \dagger$ & $3764(68.5) \dagger$ & $347(69.1) \dagger$ \\
\hline $\mathrm{NHB}$ & $416(6.9) \dagger$ & $91(12.4) \dagger$ & $378(6.9) \dagger$ & $38(7.6) \dagger$ \\
\hline Hispanic & $943(15.7) \dagger$ & $119(16.2) \dagger$ & $876(15.9) \dagger$ & $67(13.3) \dagger$ \\
\hline Asian/Other & $527(8.8) \dagger$ & $68(9.3) \dagger$ & $477(8.7) \dagger$ & $50(10.0) \dagger$ \\
\hline \multicolumn{5}{|l|}{ Child's sex } \\
\hline Female & $3031(50.5) \dagger$ & $263(35.8) \dagger$ & $2796(50.9) \dagger$ & $235(46.8) \dagger$ \\
\hline \multicolumn{5}{|l|}{ Maternal nativity } \\
\hline US-born & $4961(82.7) \dagger$ & $630(85.8) \dagger$ & $4522(82.3) \dagger$ & $439(87.5) \dagger$ \\
\hline \multicolumn{5}{|l|}{ Child health insurance in spring of kindergarten } \\
\hline Insured & $5574(92.9) \dagger$ & $693(94.4) \dagger$ & $5101(92.8) \dagger$ & $473(94.2) \dagger$ \\
\hline \multicolumn{5}{|l|}{ BMI in kindergarten } \\
\hline Lean/normal & $4473(74.6) \dagger$ & $484(65.9) \dagger$ & $4115(74.9) \dagger$ & $358(71.3) \dagger$ \\
\hline Overweight & $884(14.7) \dagger$ & $124(16.9) \dagger$ & $807(14.7) \dagger$ & $77(15.3) \dagger$ \\
\hline Obese & $640(10.7) \dagger$ & $126(17.2) \dagger$ & $573(10.4) \dagger$ & $67(13.3) \dagger$ \\
\hline
\end{tabular}

${ }^{*}$ The instances of $\mathrm{n}$ in third grade and in fifth and eighth grades include cases without missing data on exposure, outcome or covariables. †Indicates that weighted $\chi^{2}$ analysis of difference between groups (no asthma vs asthma) within wave was significant $(p<0.001)$.

BMI, body mass index; ECLS-K, Early Childhood Longitudinal Study-Kindergarten; NHB, non-Hispanic Black; NHW, non-Hispanic White.

OR 0.85 (95\% CI 0.83 to 0.86$)$ ), whereas food insecurity (vs food security) in the year before third grade was associated with a $55 \%$ higher odds (95\% CI 1.53 to 1.58$)$ (table 4). Parental depression in the spring of kindergarten and in third grade, being NHB or Asian/Other (vs NHW), being male (vs female) and being overweight or obese (vs normal/lean) in kindergarten were associated with higher odds of asthma in fifth or eighth grade (vs never) (table 4). Living in poverty (vs at or above poverty) in the year prior to kindergarten, being a Hispanic (vs NHW), having a foreign-born (vs US-born) mother and being uninsured (vs insured) in the year prior to kindergarten were associated with lower odds of asthma in fifth or eighth grade (vs never) (table 4).

To further probe the finding that living in poverty (vs at or above poverty) was associated with decreased odds of asthma by third grade and by fifth or eighth grades and the possibility that households below the poverty line coped by use of assistance programmes, we calculated $\chi^{2}$ tests to compare households below versus at/above the poverty line in kindergarten and use of either: (1) AFDC (Aid to Families with Dependent Children)/TANF (Temporary
Assistance for Needy Families) or (2) food stamps, in the preceding 12 months. Living below the poverty line (vs at/above it) was significantly associated with higher use of AFDC/TANF and of food stamps in the preceding 12 months ( $\mathrm{p}<0.001$, data not shown). Specifically, $19.2 \%$ of those below the poverty level in kindergarten received AFDC/TANF in the preceding 12 months, versus $1.1 \%$ of those at or above the poverty level. Likewise, $50.2 \%$ of those below the poverty level in kindergarten received food stamps in the preceding 12 months, versus 3.3\% of those at or above the poverty level (data not shown).

\section{DISCUSSION}

In a longitudinal cohort study of children followed from kindergarten through eighth grade, children of parents who reported household food insecurity in the year before kindergarten had a 33\% higher odds of asthma at third grade. The magnitude of this association from food insecurity before kindergarten decreased to $18 \%$ and remained significant when household food insecurity in the year before third grade was added to the model; this more 
Table 2 Characteristics ( $n, \%$ ) of the ECLS-K cohort by household food security status at the kindergarten and third grade waves* $^{*}$

\begin{tabular}{|c|c|c|c|c|}
\hline & \multicolumn{2}{|c|}{ Kindergarten (1999) } & \multicolumn{2}{|c|}{ Third grade (2002) } \\
\hline & $\begin{array}{l}\text { Food secure } \\
(n=6264)\end{array}$ & $\begin{array}{l}\text { Food insecure } \\
(n=467)\end{array}$ & $\begin{array}{l}\text { Food secure } \\
(n=6346)\end{array}$ & $\begin{array}{l}\text { Food insecure } \\
(n=385)\end{array}$ \\
\hline Parental depression in spring of third grade (yes) & $682(10.9) \dagger$ & $144(30.8) \dagger$ & $667(10.5) \dagger$ & $159(41.3) \dagger$ \\
\hline \multicolumn{5}{|l|}{ Household poverty in year before kindergarten } \\
\hline \multicolumn{5}{|l|}{ Race/ethnicity } \\
\hline NHW & $4376(69.9) \dagger$ & $191(40.9) \dagger$ & $4407(69.4) \dagger$ & $160(41.6) \dagger$ \\
\hline NHB & $452(7.2) \dagger$ & $55(11.8) \dagger$ & $449(7.1) \dagger$ & $58(15.1) \dagger$ \\
\hline Hispanic & $904(14.4) \dagger$ & $158(33.8) \dagger$ & $947(14.9) \dagger$ & $115(29.9) \dagger$ \\
\hline Asian/Other & $532(8.5) \dagger$ & $63(13.5) \dagger$ & $543(8.6) \dagger$ & $52(13.5) \dagger$ \\
\hline US-born & $5270(84.1) \dagger$ & $321(68.7) \dagger$ & $5318(83.8) \dagger$ & $273(70.9) \dagger$ \\
\hline \multicolumn{5}{|l|}{ Child health insurance in spring of kindergarten } \\
\hline Insured & $5874(93.8) \dagger$ & $393(84.2) \dagger$ & $5945(93.7) \dagger$ & 322 (83.6)† \\
\hline \multicolumn{5}{|l|}{ BMI in kindergarten } \\
\hline Lean/normal & $4619(73.7) \dagger$ & $338(72.4) \dagger$ & $4695(74.0) \dagger$ & $262(68.1) \dagger$ \\
\hline Overweight & $946(15.1) \dagger$ & $62(13.3) \dagger$ & $950(15.0) \dagger$ & $58(15.1) \dagger$ \\
\hline Obese & 699 (11.2)† & 67 (14.3)† & 701 (11.0)† & $65(16.9) \dagger$ \\
\hline
\end{tabular}

*The instances of $\mathrm{n}$ in kindergarten and in third grade include cases without missing data on exposure, outcome or covariables ( $\mathrm{n}=6731)$. †Indicates that weighted $\chi^{2}$ analysis of difference between groups (food secure vs insecure) within wave was significant ( $\left.p<0.001\right)$.

BMI, body mass index; ECLS-K, Early Childhood Longitudinal Study-Kindergarten; NHB, non-Hispanic Black; NHW, non-Hispanic White.

proximal exposure to food insecurity was associated with a $53 \%$ higher odds of asthma in third grade. Similarly, children whose parents reported household food insecurity in the year before third grade had a 55\% higher odds of asthma at fifth and eighth grades. In contrast, household food insecurity in the year before kindergarten was associated with a lower odds of asthma by fifth or eighth grade after removal of children with asthma before third grade. We are the first to report a strong, persistent signal from proximal exposure to food insecurity and a signal from exposure to food insecurity prior to kindergarten in association with a higher odds of asthma in a longitudinal study. The associations between the remaining covariates in each model and asthma were largely consistent with prior research.

Of note, exposure to parental depression in kindergarten was consistently associated with a higher odds of asthma by third grade and by fifth or eighth grades. Exposure to parental depression appears to have more chronic effects on a child's risk of asthma than food insecurity. Our results are in accord with cumulative exposure to maternal depression, versus minimal or no exposure, that was associated with nearly triple the odds of asthma in Australian offspring, independent of genetic and environmental risks. ${ }^{16}$ The association is likely mediated by both sociobiological and behavioural pathways. ${ }^{16} 272930$ Parental depression may influence development of asthma via dysregulation of the hypothalamic-pituitary-adrenal axis. ${ }^{16}$ Behavioural pathways connecting parental depression to child asthma may include parenting behaviours such as parental sensitivity and growth-fostering behaviours, and the child's perceived level of family/home stress. ${ }^{29} 30$ Parental depression could negatively affect parenting behaviours and increase a child's perceived stress level, contributing to negative health outcomes in the child. To our knowledge, no prior US study has reported the relationship between parental depression and asthma in offspring.

Household poverty was associated with decreased odds of asthma by third grade and by fifth or eighth grades when exposure to household food insecurity in the years before kindergarten and third grade and other child and parental variables were controlled. This goes against the grain of previous studies, which have shown low family incomes associated with increased odds of asthma; one study found a protective effect against asthma in 14 year olds if the family had risen out of poverty earlier in childhood. ${ }^{31}{ }^{32}$ Living below the poverty line (vs at/above it) was significantly associated with higher use of AFDC/ TANF and of food stamps in the preceding 12 months $(\mathrm{p}<0.001$, data not shown). The receipt of assistance in 
Table 3 Adjusted ORs (with 95\% Cls) for third grade asthma diagnosis by exposure to household food insecurity in years prior to kindergarten and third grade, sociodemographics and anthropometrics in the ECLS-K cohort*

\section{ORs $(95 \% \mathrm{Cls}) \quad$ ORs $(95 \% \mathrm{Cls})$}

Household food security in year prior to kindergarten

$\begin{array}{lll}\text { Food secure } & \text { Reference } & \text { Reference } \\ \text { Food insecure } & 1.33(1.31 \text { to } 1.34) \dagger & 1.18(1.17 \text { to 1.20)† } \\ \text { Household food security in second grade } & \end{array}$

\begin{tabular}{|c|c|c|}
\hline \multicolumn{2}{|l|}{ Food secure } & Reference \\
\hline \multicolumn{2}{|l|}{ Food insecure } & $1.53(1.51$ to 1.55$) \dagger$ \\
\hline \multicolumn{3}{|c|}{ Parental depression in spring of kindergarten } \\
\hline Not depressed & Reference & Reference \\
\hline Depressed & $1.15(1.14$ to 1.16$) \dagger$ & $1.11(1.10$ to 1.12$) \dagger$ \\
\hline
\end{tabular}

Household poverty in year prior to kindergarten

$\begin{array}{lll}\begin{array}{l}\text { At/above poverty } \\ \text { level }\end{array} & \text { Reference } & \text { Reference } \\ \begin{array}{l}\text { Below poverty } \\ \text { level }\end{array} & 0.87(0.86 \text { to } 0.88) \dagger & 0.84(0.83 \text { to } 0.85) \dagger \\ & & \end{array}$

Race/ethnicity

\begin{tabular}{|c|c|c|}
\hline NHW & Reference & Reference \\
\hline $\mathrm{NHB}$ & 1.66 (1.64 to 1.67$) \dagger$ & $1.62(1.60$ to 1.63$) \dagger$ \\
\hline Hispanic & $1.14(1.13$ to 1.15$) \dagger$ & $1.11(1.10$ to 1.13$) \dagger$ \\
\hline Asian/Other & $1.58(1.56$ to 1.60$) \dagger$ & $1.56(1.54$ to 1.59$) \dagger$ \\
\hline \multicolumn{3}{|l|}{ Child's sex } \\
\hline Female & Reference & Reference \\
\hline Male & 1.53 (1.52 to 1.54$) \dagger$ & 1.57 (1.56 to 1.58$) \dagger$ \\
\hline \multicolumn{3}{|l|}{ Maternal nativity } \\
\hline US-born & Reference & Reference \\
\hline Foreign-born & $0.58(0.57$ to 0.59$) \dagger$ & $0.60(0.59$ to 0.60$) \dagger$ \\
\hline \multicolumn{3}{|c|}{ Child health insurance in year prior to kindergarten } \\
\hline Insured & Reference & Reference \\
\hline Uninsured & 0.85 (0.84 to 0.86$) \dagger$ & $0.84(0.83$ to 0.85$) \dagger$ \\
\hline \multicolumn{3}{|c|}{$\mathrm{BMI}$ in kindergarten } \\
\hline Lean/normal & Reference & Reference \\
\hline Overweight & $1.27(1.26$ to 1.29$) \dagger$ & $1.27(1.26$ to 1.28$) \dagger$ \\
\hline Obese & 1.95 (1.93 to 1.97$) \dagger$ & $1.93(1.91$ to 1.94$) \dagger$ \\
\hline
\end{tabular}

${ }^{*} \mathrm{~N}$ in third grade includes cases without missing data on exposure, outcome or covariables $(n=6731)$.

†Indicates $p$ for significance $<0.001$.

BMI, body mass index; ECLS-K, Early Childhood Longitudinal Study-Kindergarten; NHB, non-Hispanic Black; NHW, nonHispanic White.

the form of AFDC/TANF or food stamps are indicators of household coping strategies and may underlie the observed association between poverty in the kindergarten year and decreased odds of asthma.

Compared with NHWs, NHB race/ethnicity was positively associated with asthma in both logistic models at third and fifth or eighth grades, while Hispanic race/ ethnicity was associated with higher odds of asthma in
Table 4 Adjusted ORs (with 95\% Cls) for asthma diagnosis in fifth or eighth grade by exposure to household food insecurity in year prior to kindergarten, sociodemographics and anthropometrics in the ECLS-K cohort*

\section{ORs (95\% Cls)}

Household food security in year prior to kindergarten
Food secure
Reference
Food insecure 0.85 (0.83 to 0.86$) \dagger$

Household food security in second grade

$\begin{array}{ll}\text { Food secure } & \text { Reference } \\ \text { Food insecure } & 1.55 \text { (1.53 to 1.58) } \dagger\end{array}$

Parental depression in spring of kindergarten

$\begin{array}{ll}\text { Not depressed } & \text { Reference } \\ \text { Depressed } & 1.42(1.41 \text { to 1.44)† }\end{array}$

Parental depression in spring of third grade
Not depressed
Reference
Depressed
1.23 (1.22 to 1.25$) \dagger$

Household poverty in year prior to kindergarten

\begin{tabular}{|c|c|}
\hline At/above poverty level & Reference \\
\hline Below poverty level & $0.91(0.90$ to 0.92$) \dagger$ \\
\hline \multicolumn{2}{|l|}{ Race/ethnicity } \\
\hline NHW & Reference \\
\hline NHB & $1.21(1.20$ to 1.23$) \dagger$ \\
\hline Hispanic & $0.88(0.87$ to 0.89$) \dagger$ \\
\hline Asian/Other & $1.71(1.68$ to 1.73$) \dagger$ \\
\hline \multicolumn{2}{|l|}{ Child's sex } \\
\hline Female & Reference \\
\hline Male & $1.37(1.36$ to 1.38$) \dagger$ \\
\hline \multicolumn{2}{|l|}{ Maternal nativity } \\
\hline US-born & Reference \\
\hline Foreign-born & $0.51(0.50$ to 0.52$) \dagger$ \\
\hline \multicolumn{2}{|c|}{ Child health insurance in year prior to kindergarten } \\
\hline Insured & Reference \\
\hline Uninsured & $0.72(0.71$ to 0.73$) \dagger$ \\
\hline \multicolumn{2}{|l|}{ BMI in kindergarten } \\
\hline Lean/normal & Reference \\
\hline Overweight & $1.23(1.22$ to 1.24$) \dagger$ \\
\hline Obese & $1.23(1.21$ to 1.25$) \dagger$ \\
\hline
\end{tabular}

${ }^{*} \mathrm{~N}$ in fifth and eighth grades includes cases without missing data on exposure, outcome or covariables and excludes children diagnosed with asthma prior to these grades $(n=5997)$. †Indicates $p$ for significance $<0.001$.

BMI, body mass index; ECLS-K, Early Childhood Longitudinal Study-Kindergarten; NHB, non-Hispanic Black; NHW, nonHispanic White.

the third grade model, but marginally lowered odds of asthma in fifth/eighth grade. These findings are largely consistent with previous research on race/ethnic disparities in childhood asthma. ${ }^{33-35}$ In cross-sectional analyses of the National Health and Nutrition Examination Survey 
(NHANES) III and the 2007 National Survey of Children's Health, NHB race/ethnicity was positively associated with asthma; genetic/family history and parental health factors are suggested to contribute to the observed disparities in asthma prevalence rates between race/ ethnicities. ${ }^{3435}$ In Hispanic children, it is possible that the epidemiological paradox, the phenomenon of better health outcomes among children of immigrants to the USA compared with their NHW counterparts, may be a factor in the lowered odds of asthma observed in fifth/ eighth grade, in contrast with the positive association with asthma odds observed in third grade, which is consistent with previous data from NHANES III. ${ }^{34-36}$ Lastly, Asian/ Other race/ethnicity was associated with a higher odds of asthma but this group was heterogeneous, including children of Asian, Native American and Pacific Islander descent, making these results difficult to interpret.

Male sex was positively associated with asthma in all models; conversely, having a mother born outside the USA was negatively associated with odds of asthma. These findings are both congruent with our previous research and other published studies. ${ }^{21}{ }^{33}$ Mechanisms hypothesised to underlie the negative association between foreign-born maternal nativity and child asthma include higher rates of breastfeeding, which is hypothesised to be protective against asthma, a negative association between foreign-born nativity and parental asthma and/or protective maternal diets during pregnancy. ${ }^{17}$ 37-39 Children that were uninsured in kindergarten had a lower odds of asthma. This finding may reflect a detection bias in those children that were insured and had access to healthcare and physician visits, and suggests that paucity of resources may globally affect a household. ${ }^{21}{ }^{35}$ In line with prior research, being overweight or obese in kindergarten was associated with a higher odds of asthma in both models. ${ }^{17} 183440$

In an attempt to explain the finding that proximal, less so earlier life, exposure to food insecurity was associated with a higher odds of asthma, we offer several possible factors or conditions within the immediate household environment for consideration. For example, exposure to food insecurity could be one link in a chain of risk, exerting deleterious effects on household routine or structure or exacerbating suboptimal living conditions, overwhelming a family's coping mechanisms in the short term. ${ }^{41-43}$ This destabilising stress, insofar as it contributes to chaotic home environments, could in turn affect children's risk of chronic disease, with or without an increase in parental emotional distress or parenting difficulties. ${ }^{42}$ Food insecurity may work across multiple domains via stress and/or associated inflammatory processes to negatively impact health and development. Although the aetiology of asthma is unknown, inflammation involved in triggering asthma is hypothesised to arise from diet-mediated increases in inflammation or metabolic changes related to pathological weight gain; poor diet with energy-dense foods may enhance that diet-mediated increase in inflammation and asthma onset. ${ }^{10131417184445}$ In contrast, our finding that food insecurity in the year before kindergarten was associated with reduced odds of asthma in fifth or eighth grades may represent long-term, as opposed to short-term, success of family coping mechanisms. Our findings highlight the importance of assessing specific windows of susceptibility to food insecurity in relation to risk of childhood asthma and related comorbidities within a life course framework. ${ }^{20} 23$

Chief among the strengths of this analysis is the examination of multiple waves of the ECLS-K that at its conclusion was representative of four out of five eighth graders in the USA. The sample design of the ECLS-K increases the likelihood that the study findings are generalisable to the US population of school-aged children. ${ }^{24}$ Additional strengths include repeated measures of food insecurity exposure and the use of the HFSSM and a validated short form of the CES-D. ${ }^{21}$ Limitations include no data collection in the ECLS-K of family history of asthma or environmental exposures associated with asthma, such as maternal smoking or child exposure to air pollutants. ${ }^{244647}$ In addition, there was $>50 \%$ loss of participants to follow up between 1998 and 2007 in the ECLS-K. ${ }^{24}$ Lastly, it is possible that the ever diagnosis of asthma in third grade could have occurred before exposure to household food insecurity in the year prior to kindergarten. Future investigations would benefit from data collection that includes: repeated measures of food insecurity; asthma diagnosis abstracted from medical records; parental BMI, smoking and asthma history; and biomarkers of inflammation or stress. In addition, a structural equations model to assess both the direct and indirect effects of these parameters might delineate more clearly the role of food insecurity from other factors not collected in this study.

To our knowledge, this is the first study exploring the relationship between timing of exposure to food insecurity and childhood asthma. Since the last wave of the ECLS-K in 2007, childhood asthma prevalence rates continued to rise, peaking at $8.3 \%$ in $2013 .{ }^{33}$ Asthma onset during the school-age years increases chances of chronic disease persistence into adulthood; therefore, identification of early-life exposures associated with asthma may enable earlier detection and treatment of asthma in highrisk populations. ${ }^{46}{ }^{48}$ Additional research with repeated measures of food security and asthma is needed to determine whether the signals from food insecurity in the year before kindergarten and in second grade represent a sensitive period for vulnerability to asthma.

Contributors LDM, MDH and MRF contributed substantially to the conception and design of the work; $\mathrm{YD}$ and $\mathrm{YZ}$ contributed to the analysis of data; all authors contributed to the interpretation of data and the final approval of the version published, with LDM, MDH and MRF primarily responsible for revising the drafts for publication.

Funding Some support was provided via Grant \#P2CHD042849, from the NICHD to the Population Research Center at the University of Texas at Austin.

Competing interests None declared.

Patient consent Not required.

Provenance and peer review Not commissioned; externally peer reviewed. 
Data sharing statement Unpublished data are stored electronically by the corresponding author and are available to interested parties at the discretion of the corresponding author and co-authors.

Open access This is an open access article distributed in accordance with the Creative Commons Attribution Non Commercial (CC BY-NC 4.0) license, which permits others to distribute, remix, adapt, build upon this work non-commercially, and license their derivative works on different terms, provided the original work is properly cited, appropriate credit is given, any changes made indicated, and the use is non-commercial. See: http://creativecommons.org/licenses/by-nc/4.0/.

\section{REFERENCES}

1. Coleman-Jensen A, Rabbitt MP, Gregory CA, et al. Household food security in the United States in 2015. Washington, D.C.: United States Department of Agriculture; Economic Research Service, 2016:44.

2. Gundersen C, Ziliak JP. Childhood food insecurity in the U.S.: trends, causes, and policy options. Future of Children: Future of Children, 2014:1-19.

3. Shankar P, Chung R, Frank DA. Association of Food Insecurity with Children's Behavioral, Emotional, and Academic Outcomes: A Systematic Review. J Dev Behav Pediatr 2017;38:135-50.

4. Holben DH, Marshall MB. Position of the Academy of Nutrition and Dietetics: Food Insecurity in the United States. J Acad Nutr Diet 2017;117:1991-2002.

5. Coleman-Jensen A, Rabbitt MP, Gregory CA, et al. Household Food Security in the United States in 2016: United States Department of Agriculture, 2017:44

6. COUNCIL ON COMMUNITY PEDIATRICSCOMMITTEE ON NUTRITION. Promoting food security for all children. Pediatrics 2015;136:e1431-8

7. Melchior M, Caspi A, Howard LM, et al. Mental health context of food insecurity: a representative cohort of families with young children. Pediatrics 2009;124:e564-72.

8. Garg A, Toy S, Tripodis Y, et al. Influence of maternal depression on household food insecurity for low-income families. Acad Pediatr 2015;15:305-10.

9. Noonan K, Corman H, Reichman NE. Effects of maternal depression on family food insecurity. Econ Hum Biol 2016;22:201-15.

10. Eisenmann JC, Gundersen C, Lohman BJ, et al. Is food insecurity related to overweight and obesity in children and adolescents? A summary of studies, 1995-2009. Obes Rev 2011;12:e73-83.

11. Larson NI, Story MT. Food insecurity and weight status among U.S. children and families: a review of the literature. Am J Prev Med 2011;40:166-73.

12. Metallinos-Katsaras E, Must A, Gorman K. A longitudinal study of food insecurity on obesity in preschool children. J Acad Nutr Diet 2012;112:1949-58.

13. Kaur J, Lamb MM, Ogden CL. The association between food insecurity and obesity in children-the national health and nutrition examination survey. J Acad Nutr Diet 2015;115:751-8.

14. Papas MA, Trabulsi JC, Dahl A, et al. Food Insecurity increases the odds of obesity among young hispanic children. J Immigr Minor Health 2016;18:1046-52.

15. Speirs KE, Fiese BH. STRONG Kids Research Team. The relationship between food insecurity and bmi for preschool children. Matern Child Health J 2016;20:925-33.

16. Giallo R, Bahreinian S, Brown S, et al. Maternal depressive symptoms across early childhood and asthma in school children: findings from a longitudinal Australian population based study. PLoS One 2015;10:e0121459.

17. Papoutsakis C, Priftis KN, Drakouli M, et al. Childhood overweight/ obesity and asthma: is there a link? A systematic review of recent epidemiologic evidence. J Acad Nutr Diet 2013;113:77-105.

18. Black $\mathrm{MH}$, Zhou $\mathrm{H}$, Takayanagi $\mathrm{M}$, et al. Increased asthma risk and asthma-related health care complications associated with childhood obesity. Am J Epidemiol 2013;178:1120-8.

19. Kuh D, Ben-Shlomo Y, Lynch J, et al. Life course epidemiology. $\checkmark$ Epidemiol Community Health 2003;57:778-83.

20. Kirkpatrick SI, Mclntyre L, Potestio ML. Child hunger and longterm adverse consequences for health. Arch Pediatr Adolesc Med 2010;164:754-62.

21. Mangini LD, Hayward MD, Dong YQ, et al. Household food insecurity is associated with childhood asthma. J Nutr 2015;145:2756-64.

22. Ribeiro-Silva RC, Oliveira-Assis AM, Junqueira SB, et al. Food and nutrition insecurity: a marker of vulnerability to asthma symptoms. Public Health Nutr 2014;17:14-19.

23. Ben-Shlomo Y, Kuh D. A life course approach to chronic disease epidemiology: conceptual models, empirical challenges and interdisciplinary perspectives. Int J Epidemiol 2002;31:285-93.
24. Tourangeau K, Nord C, Le T, et al. Early Childhood Longitudinal Study, Kindergarten Class of 1998-99 (ECLS-K): Combined User's Manual for the ECLS-K Eighth-Grade and K-8 Full Sample Data Files and Electronic Codebooks. Washington, DC: NCES 2009-004: National Center for Education Statistics, 2009.

25. USDA. Food Security in the United States: definitions of hunger and food security. $2011 \mathrm{http}: / /$ www.ers.usda.gov/topics/foodnutrition-assistance/food-security-in-the-us/measurement.aspx\#. Udr58FNQ36Y

26. Winer RA, Qin X, Harrington T, et al. Asthma incidence among children and adults: findings from the Behavioral Risk Factor Surveillance system asthma call-back survey-United States, 20062008. J Asthma 2012;49:16-22.

27. Silverstein $M$, Augustyn $M$, Cabral $H$, et al. Maternal depression and violence exposure: double jeopardy for child school functioning. Pediatrics 2006;118:e792-800.

28. Barlow SE. Expert Committee. Expert committee recommendations regarding the prevention, assessment, and treatment of child and adolescent overweight and obesity: summary report. Pediatrics 2007;120(Suppl 4):S164-92.

29. Koinis-Mitchell D, Kopel SJ, Salcedo L, et al. Asthma indicators and neighborhood and family stressors related to urban living in children. Am J Health Behav 2014;38:22-30.

30. Bronte-Tinkew J, Zaslow M, Capps R, et al. Food insecurity works through depression, parenting, and infant feeding to influence overweight and health in toddlers. J Nutr 2007;137:2160-5.

31. Kozyrskyj AL, Kendall GE, Jacoby P, et al. Association between socioeconomic status and the development of asthma: analyses of income trajectories. Am J Public Health 2010;100:540-6.

32. Keet CA, McCormack MC, Pollack CE, et al. Neighborhood poverty, urban residence, race/ethnicity, and asthma: Rethinking the inner-city asthma epidemic. J Allergy Clin Immunol 2015;135:655-62.

33. Akinbami LJ, Simon AE, Rossen LM. Changing trends in asthma prevalence among children. Pediatrics 2016;137:e20152354-7.

34. Rodríguez MA, Winkleby MA, Ahn D, et al. Identification of population subgroups of children and adolescents with high asthma prevalence: findings from the Third National Health and Nutrition Examination Survey. Arch Pediatr Adolesc Med 2002;156:269-75.

35. Kitsantas P, Kornides ML, Cantiello J, et al. Chronic physical health conditions among children of different racial/ethnic backgrounds. Public Health 2013;127:546-53.

36. Markides KS, Coreil J. The health of Hispanics in the southwestern United States: an epidemiologic paradox. Public Health Rep 1986;101:253-65.

37. Yong SB, Wu CC, Wang L, et al. Influence and mechanisms of maternal and infant diets on the development of childhood asthma. Pediatr Neonatol 2013;54:5-11.

38. Bandoli G, von Ehrenstein OS, Flores ME, et al. Breastfeeding and asthmatic symptoms in the offspring of Latinas: the role of maternal nativity. J Immigr Minor Health 2015;17:1739-45.

39. Brugge D, Woodin M, Schuch TJ, et al. Community-level data suggest that asthma prevalence varies between U.S. and foreignborn black subpopulations. J Asthma 2008;45:785-9.

40. Chen YC, Dong GH, Lin KC, et al. Gender difference of childhood overweight and obesity in predicting the risk of incident asthma: a systematic review and meta-analysis. Obes Rev 2013;14:222-31.

41. Matheny AP, Wachs TD, Ludwig JL, et al. Bringing order out of chaos: psychometric characteristics of the confusion, hubbub, and order scale. J Appl Dev Psychol 1995;16:429-44.

42. Dumas JE, Nissley J, Nordstrom A, et al. Home chaos: sociodemographic, parenting, interactional, and child correlates. J Clin Child Adolesc Psychol 2005;34:93-104.

43. Pinard CA, Calloway EE, Fricke HE, et al. A cross-sectional exploration of food security, depression, and CHAOS in low-income households with children. J Appl Res Children 2015;6:13.

44. Bernal J, Frongillo EA, Rivera JA. Food insecurity reported by children, but not by mothers, is associated with lower quality of diet and shifts in foods consumed. Matern Child Nutr 2016;12:546-57.

45. Lee AM, Scharf RJ, DeBoer MD. Association between kindergarten and first-grade food insecurity and weight status in U.S. children. Nutrition 2018;51-52:1-5.

46. Beasley R, Semprini A, Mitchell EA. Risk factors for asthma: is prevention possible? The Lancet 2015;386:1075-85.

47. Jaakkola JJ, Gissler M. Maternal smoking in pregnancy, fetal development, and childhood asthma. Am J Public Health 2004;94:136-40.

48. Sears MR, Greene JM, Willan AR, et al. A longitudinal, populationbased, cohort study of childhood asthma followed to adulthood. N Engl J Med 2003;349:1414-22. 